\title{
Meals in western eating and drinking
}

\author{
Niva, Mari
}

Springer

2020

Niva , M \& Mäkelä , J 2020 , Meals in western eating and drinking . in H L Meiselman (ed.) , Handbook of eating and drinking : Interdisciplinary perspectives. Springer, Cham, pp. 495-508 . https://doi.org/10.1007/978-3-319-75388-1_125-1

http://hdl.handle.net/10138/333123

https://doi.org/10.1007/978-3-319-75388-1_125-1

unspecified

acceptedVersion

Downloaded from Helda, University of Helsinki institutional repository.

This is an electronic reprint of the original article.

This reprint may differ from the original in pagination and typographic detail.

Please cite the original version. 
Publication information: Niva, Mari \& Mäkelä, Johanna (2019). Meals in western eating and drinking. In: Handbook of eating and drinking. Interdisciplinary perspectives, ed. by $\mathbf{H}$ Meiselman. https://doi.org/10.1007/978-3-319-75388-1_125-1.

This is an almost final version before publication (without some stylistic changes in the published text).

\title{
Meals in Western Eating and Drinking
}

Mari Niva \& Johanna Mäkelä

\begin{abstract}
Meals are a way of organizing eating into events that have a particular structure and form, and they play an indisputable and even self-evident role in the rhythms and routines of everyday life. In late modern societies, concern about the fate of meals has arisen in both public and academic discourse. It has been suggested that eating is characterized today by individualization, destructuration, and informalization and that communal meals are increasingly being replaced by snacks and solitary eating. This chapter focuses on meals in today's affluent societies and reflects on why meals are considered important, how meals are defined, and what material elements and social dimensions they contain. It looks at how societal and cultural changes and ecological concerns may influence the organization and future of meals, and it suggests that the content of meals will change in response to the need to diminish the ecological burden of food production and consumption. In particular, plant-based options will at least partly need to replace meat and other animal-based foods. However, there is no reason to expect that the meal as a social institution will break down. Despite the fact that not all meals are characterized by conviviality and companionship, they continue to serve as a significant arena of human sociability and togetherness. Sharing food is, after all, an essential part of humanity.
\end{abstract}

Introduction: Why Do Meals Matter?

Meals are considered to be a profound part of human sociality, and they are important in our lives in numerous ways, both practically and symbolically. In the practical sense, food is fundamental in keeping us alive and going, and what is eaten at meals is significant for both short- and long-term health and wellbeing. Procuring food, planning and preparing meals, eating, and cleaning up afterward take up a significant portion of our waking hours, and meals both shape and are shaped by the schedules and rhythms of daily life. Meals punctuate our days and separate weekdays from weekends and the everyday from the feast. Buying food demands financial resources, and, for those with small incomes, finding the money to obtain food that is both liked and nutritionally adequate may be a constant struggle and cause of distress (Holm et al. 2018).

In the symbolic sense, meals signify diners' positions in their social networks and reflect their cultural and culinary capital as well as their ideas about what is good and proper eating. The characteristics of the foods that are eaten and the social organization of a meal, such as how and by whom it is cooked and with whom and at what level of formality it is enjoyed, are all loaded with symbolic meaning. It is difficult to find any "occasion for significant human interaction" in which food does not play a role; a celebration or other important gathering without communal eating would be most exceptional (Lalonde 1992, p. 71). As Mary Douglas (1972) has noted, the ways in 
which people orchestrate their eating into meals reflect the forms of social relationships of which they are the core. Sharing a meal with somebody is a sign of belonging to a particular community. Food communicates who people are within their communities and social relations, and both the symbolic meanings and practical organization of meals may differ according to the diners' social positions (Bourdieu 1979, 1984).

Contemporary ideas about good eating are informed by a range of food-related discourse on such topics as healthiness, family communion, commensality, good taste (in both the sensorial and sociocultural meanings of the word), expectations of the preferences of diners, know-how and skills in cooking, and, increasingly today, concerns about what is sustainable in terms of eating. The cook and the person eating are now expected to take a stand not only on the "private virtues" implied by the consumption of food, such as taste, price, convenience, and nutritional value, but also on the "public virtues" relating to the wider society, such as ethics, justice, and ecological impact (Micheletti 2003; Niva and Jallinoja 2018). Such expectations broaden the scope of what good meals and eating are about and make new demands on consumers and meal providers to eat in socially and environmentally responsible ways.

The current discourse on food and eating often centers on food choice, a term adopted in both popular discourse and in many disciplines. Individualistic in its tone (see Murcott 1998), food choice is used as a general denominator of what people choose to eat and the individual characteristics, motivations, and attitudes influencing their choices. From the perspective of everyday life, however, where most eating takes place in the context of meals, one might ask whether it would be more useful in studies of eating to think of meals rather than food choices as the analytical unit of investigation. In his reflection on how meals influence food choices, David Marshall (1993) concludes that not only acceptability but also appropriateness to purpose is essential when people consider what food to eat. Appropriateness refers to the context in which the food is to be consumed and embraces the type of eating event (breakfast, lunch, dinner, or snack), the social company, and the formality of the eating event (see Giacalone 2019 on the application of appropriateness in consumer and sensory sciences). The food has to fit within the "meal system" (Marshall 1993, p. 280) of the household and accord with various often implicit rules concerning what, how, and when it is appropriate to eat. In this way, appropriateness determines what is chosen as food. Similarly, in a later chapter, Marshall (2005) contends that the meanings of food reside more in the routines, conventions, and rituals of meals than in the foods that are eaten at them. In this sense, food choice can be seen as subordinate to how meals are socially organized and regulated in the routines and habits of everyday life (see also Warde 2016; Murcott 2019).

There are strong social norms around meals. As noted in the Introduction, one of the more important norms relates to commensality (Fischler 2011), that is, eating at the same table with other people and sharing food with them. Numerous studies have shown that commensality is regarded as an essential part of eating and of what is considered to be a "proper" meal (eg., Mäkelä 2009; Charles and Kerr 1988). For instance, Sobal and Nelson (2003) emphasize the significance of commensal ity by rephrasing the saying "you are what you eat" to "you are who you eat with" (p. \#). Social psychologists use the concept of social facilitation to describe the tendency of people to adapt to other people's eating in social situations (Higgs et al. 2019). For instance, people often adjust what and how much they eat to the behavior of significant others present in the situation. The commensal units and circles (Sobal and Nelson 2003) in which people operate reflect social relationships in family life, work, and society at large. The most important commensal unit is the family, followed by groups of people getting together for lunch or coffee at work. The term commensal circle refers to a wider network of people who could, in principle, take part in a meal, with the family still at the core of the circle. 
Due to the strong connotation of eating together as a sign of family communion, family meals have been described as the "archetype" of commensality, with the combination of food and family creating an idealized "symbolic icon" (Sobal et al. 2002, pp. 391-392). Families are seen to reaffirm their cohesion by eating together, and those failing to do so are dismissed as failed families. So powerful is the social norm of family eating that food providers, particularly in middleclass families, tend to praise commensal eating as the ideal although that does not necessarily mean that they are able to eat family meals regularly (Backett-Milburn et al. 2010) or that meal provision is something that parents actually enjoy. Kinser's (2017) study shows that, even though mothers work hard to cook and share meals with their families, they may have decidedly mixed emotions about the obligation and responsibility to do so. The participants in Kinser's focus group provided meals at the expense of their own needs and interests and struggled to arrange family meals for "the health of it, and ... for thestatus of it" (p. 38). Overall, their accounts of family meal provision were characterized by notions of work, burden, battle, fighting, and control. As the quotation shows, the mothers were well aware of not only the claimed benefits but also the social value and normative expectations of family meals.

Such everyday struggles are forgotten, however, when the ideal of the family meal is celebrated in both public discourse and in numerous psychological, nutritional, and social-scientific studies that demonstrate the multiple benefits to children of regular family dinners. Adolescents who frequently eat a family meal have lower odds of cigarette smoking, alcohol use, and drug experimentation even when controlling for family structure and parental education and employment (Mure et al. 2014). Brown et al. (2019) show that adolescents who feel loved by their parents and like to spend time with them are more likely to eat family meals than others. Studies also show that adolescents and young adults themselves value family meals (e.g., Hunt et al. 2011), so it is no wonder that parents see it as their responsibility to provide the shared experiences of eating with their children. School meals are also expected to be commensal events that enhance the school community and lead to better academic performance, improved behavior, and more energetic children (Elliott and Hore 2016).

Shared meals are lauded not only by families with children but also by newlyweds and cohabiting couples. Marshall and Anderson (2002) found that, for young Scottish couples, a shared dinner was an important part of living together and spending time with one's partner and that "eating properly" was a metaphor of family life (p. \#). Similarly, according to Sobal et al. (2002), eating together is a major spousal obligation through which newlywed couples in the US negotiate their "food lives" so as to enjoy commensal meals within "doing marriage" and strengthening their conjugal ties (p. \#). So-called proper meals involve eating with a proper person; for newlyweds, that is self-evidently the spouse.

Such is the power of the ideal of shared meals that eating alone is frowned upon. A lonely diner is pitied, and people are assumed to prefer eating in company if they have the opportunity to do so. Indeed, a person declining the company of others at a meal is regarded as strange because people are expected to share their food (Fischler 2011). It has been found, however, that older people who live alone may actually enjoy eating alone, deciding by themselves when and what to eat, and not having to worry about other people's preferences. Eating in solitude may thus symbolize control, independence, and competence (Thomas and Emond 2017). At the same time, a growing body of literature focuses on solo dining, understood as eating alone in the public sphere (e.g., Lahad and May 2017). Some solo diners may dine alone because they are travelling alone while others may take great pleasure in going out for a solitary meal to enjoy the dining experience and taste of food without having to socialize (beyond discussing the food with the restaurant staff). 
An important element of commensality has been the idea of sharing the same food, but this ideal has not always been fulfilled in practice. Historically, there is evidence of privileging men's nutritional needs over those of women, with women obliged to settle for inferior food compared to men (Murcott 2019). Research in Britain in the 1980s showed that, in unemployed families with tight budgets, women would do without meat and fish so that their husbands and children could eat adequately (Charles and Kerr 1986). Interestingly, the variation in foods eaten at a shared meal today is often based on individual choices and dietary restrictions rather than differences in family members' autonomy and power relations. Allergies, chronic illnesses, and the increasing popularity of, for instance, vegetarian and vegan diets pose challenges to the ideal of a meal as an event for eating and enjoying the same food (on veganism, see the chapters in this book's section on the ethics of eating; on vegan diets and family conflicts, see, e.g., Roth 2005).

What Is a Meal?

Contemporary Western eating can usefully be described as an eating system (Mäkelä et al. 1999; see also Gronow and Holm 2019). This system includes three dimensions: the eating pattern (the rhythm and the number of eating events as well as the alternations of hot and cold eating events), the meal format (the composition of the main course and the sequence of the whole meal), and the social organization of eating (where and with whom people eat and who did the cooking). In a similar vein, Yates and Warde (2015, p. 300) define the cultural complex of a meal as comprising the foods and dishes that are served, the patterning of the eating events (i.e., the structure of the sequential episodes), the format of the event (i.e., the organization of dishes in parallel and in series), the preparation and provisioning of the meal, and, finally, the social occasion of the event. Lalonde (1992) has suggested four interpretations of a meal: It can be thought of as a "timely repast," as an object with a particular structure, as "scripted" action with certain objectives, or as a socially meaningful event (p.\#).

The roots of exploring meals as a vital part of people's everyday lives can be traced to British meal research in the 1970s and 1980s. Scholars such as anthropologist Mary Douglas (1972, 1997; see also Douglas and Nicod 1974) and sociologist Anne Murcott (1982) explored British working class and Welsh middle-class meals to pinpoint the grammar of a "decent" and "proper" meal in the British context. In their classic article, Douglas and Nicod (1974) describe the structural and taste characteristics of meals using the binary pairs of salty/sweet, hot/cold, and liquid/dry. In addition, they found that the classifications of meals were based on their abundance, complexity, and ceremonial aspects. According to Douglas and Nicod, the British working-class meal model comprises many distinct, complementary, and often contradictory classifications.

Douglas and Nicod (1974) devised a meal taxonomy that comprises three meal types. The first is a major meal or the main meal (A), the second is a minor meal or the second meal (B), and the third category consists of even less significant meals, or third meals (C) (Douglas and Nicod 1974). They found that the meal categorized as a main meal in Britain was based on the elements of a staple (potato), a center (meat, fish, or egg), trimmings (vegetables), and dressing (gravy). Anne Murcott (1982) pursued the same approach in her work on proper meals in South Wales. Not surprisingly, she found that a proper meal possessed the same structure that Douglas and Nicod had found: It consisted of one meat-based course, two vegetables, and gravy, which tied the ingredients on the plate into a proper meal. Indeed, a proper meal was a plateful of ingredients that were carefully chosen to represent a particular element of a meal. 
The British meal research tradition has been very influential worldwide but especially in the Nordic countries (see, e.g., Gronow and Holm 2019). In the late 1980s, Marianne Ekström (1990) applied the idea of a grammar of meals in her study of Swedish meals. She concluded that a cooked (i.e., proper) meal consists of four components. The main ingredient was usually meat or fish, the first trimming was the starchy element (e.g., potatoes), and the second trimming comprised vegetables. Finally, extra trimmings could be vegetables or condiments. Later in the 1990s, a research project on Nordic meal patterns (Kjærnes 2001) defined a proper meal in the Nordic countries as a plate of food consisting of at least three elements: a center (C), a staple (S), and vegetables (V) or, instead of vegetables, bread (B). In addition, a proper meal might include trimmings, such as sauces, condiments, or pickles (see Mäkelä 2001). A study in 2012 found that dinners in the Nordic countries are still typically one-course meals with relatively simple structures (see Holm et al. 2019 in this collection). This Nordic meal model contrasts with, for instance, Italian or French traditions favoring meals with several courses (Poulain 2017).

As the above examples of meal research suggest, eating events are largely organized around meals, be they minor, such as breakfast, or major, such as lunch during the day and dinner in the evening. These are concepts that people in developed countries know so well that they are essentially selfevident (e.g., Marshall 1993). When talking about breakfast, for instance, people generally assume that others can infer not only that they mean a morning meal but also that it includes certain culturally specific but recognizable elements. Bread is an example of a breakfast item identifiable across Europe whereas bacon, eggs, and beans would be associated with an English breakfast and a croissant with a French one. Similarly, lunch in the contemporary vocabulary refers to a meal that is typically larger than breakfast and takes place later in the day, around noon or somewhat later.

Lunch may be hot or cold, depending on national and cultural traditions and institutional arrangements relating to work and school life (e.g., Holm et al. 2019). Dinner is assumed to be the major meal of the day, often with a culturally specific established structure varying from one-course to several-course meals. As with lunch, typical dinner times vary from country to country, and there are also in-country variations. In the Nordic countries, for instance, hot dinner usually takes place between 4:00 and 8:00 p.m. (Holm et al. 2015) with nationally varying peak times (Bøker Lund and Gronow 2014). Thus, even though Western food cultures seem to share the idea of breakfast, lunch, and dinner as meal events taking place at certain times of the day, their structures and practices vary somewhat.

A snack, which is generally considered to be not a meal but a separate, more unstructured type of eating event (see Marshall 1993, 2005; Warde and Yates 2017), is a more arbitrary concept. A snack can take place at any time between meals, and there are typically no strict rules about its content or where it should be consumed. We may note that this distinction between meals and snacks is itself a token of the social and cultural significance of meals. However, as Warde and Yates (2017) have noted, meals and snacks should not be understood as diametrically opposed to each other but rather as different types of eating events. The increasing consumption of snacks is often somewhat disapprovingly referred to as grazing (e.g., Fischler 2011), but the fact that the number of eating events per day is slightly increasing (Bøker Lund and Gronow 2014; Poulain 2017) suggests that snacks are becoming more important in contemporary eating.

\section{Changing Meals}

Meal patterns are culturally specific and change over time. Although the discourse on meals during the past few decades has fretted over the individualization and destructuration of meals (see Mäkelä 2009; Gronow and Holm 2019), research has shown that individually varying mealtimes were not uncommon in earlier decades and centuries. In eighteenth- and nineteenth-century France, the 
mealtimes and number of daily meals varied according to the diners' social positions, and not all family members necessarily ate together (Flandrin 1996). In nineteenth-century Britain, upper-class children never ate with their parents, and, unlike their parents, they were served a very limited variety of foods (Murcott 1997). The names of meals at various times of the day have changed too; in France, what was formerly termed dîner (dinner) is now known as déjeuner (lunch) (Flandrin 1996). Similar changes have taken place in other countries. In the USA, industrialization and the emergence of (male) professions in cities in the late 1800s gradually led to a shift from eating a large meal at midday to eating the main meal in the evening (Erby 2017). In Finland, breakfast in the 1920s was still a full, hot meal similar to lunch and dinner. Breakfast evolved from a hot meal to a coffee-with-bread eating event only when working days were shortened by legislation to eight hours and coffee became affordable to the working class (Prättälä et al. 1993). In 1950s Britain, over $40 \%$ of the population had a hot weekday breakfast (typically bacon and eggs) whereas only 6\% did the same in 2012 (Yates and Warde 2015).

Erby (2017) suggests that, in the USA, the idealization of the family meal started in the mid-1800s, when industrialization, market capitalism, and individualism began to influence the dynamics of family life. While men increasingly worked in paid labor outside the home, women, at least in the more affluent households, stayed home and were expected to focus on the domestic realm. It was their task to provide meals, which now acquired new meanings as tokens of caring for the children and the husband (so that he could enjoy the homely atmosphere and gather strength at home both during the midday break and after a hard day's work). The American family meal was born out of this romanticizing of the home as a "wellspring of virtue and love" (Erby 2017, p. 674). At the same time, attention was now paid to table manners, moderation in eating, and the foods served at meals. In the middle-class domestic ideal, family meals were an arena for practicing self-restraint and proper behavior.

As these and other examples show, industrialization, economic development, and changes in working schedules outside the home have primarily been responsible for large-scale societal changes in mealtimes and the social organization of meals over the past 200 years (Flandrin 1996; Prättälä et al. 1993). Similarly, in affluent contemporary societies, what people eat and when and with whom they take their meals are to a large extent demarcated by the increasing share of single households and non-nuclear families, the urban way of life, the working hours of adults, the school schedules and extracurricular activities of children, and the commodified and commercialized organization of the food supply (see, e.g., Gronow and Holm 2019; Murcott 2019). The organization of meals can thus be seen as an indicator of how, in a given society, everyday life is configured around paid work, household work, school, and leisure-at least for the majority who participate in work or educational institutions.

In the past few decades, both popular and academic discourse has raised concerns about a general destructuration and individualization of eating, including the "demise" of meals, particularly shared meals, which have allegedly been replaced by grazing and snacking (Fischler 2011). In the social sciences, one of the more widely cited proponents of this view is the French sociologist and anthropologist Claude Fischler, whose concept of gastro-anomy has gained wide popularity in discussions about the decline of meals. However, as Anne Murcott (2019) has pointed out, there is more evidence of a century-long concern about the decline in family meals than of such a decline's having actually taken place. She has also noted that the middle-class family has come to represent the ideal family, and it is against this ideal that many commentators worry about the decline of family meals (Murcott 1997). Similarly, Andersen and Hedegaard Larsen (2015) note that the myth of the vanishing family meal emerged from the idealization of times past and serves the interests of those who wish to criticize modern "unheal thy and unsociable" ways of eating (Andersen and 
Hedegaard Larsen 2015, p. 287). Furthermore, it should be noted that the meanings of concepts such as meal and family change over time and vary in diverse cultural contexts.

As social scientists have pointed out, the celebration of commensal and family meals rarely acknowledges that commensality does not always equal conviviality. Meals also involve power struggles over what, how much, and when to eat and over the gendered division of responsibility in providing meals; they are occasions when the potentially tense relationships in a family become evident (e.g., Andersen and Hedegaard Larsen 2015; Murcott 1986, 2019; Roth 2005). Andersen and Hedegaard Larsen (2015) argue that the family meal should be seen "as a symptom of a happy family rather than its cause or as a solution for making families (more) happy" (p. 289). The celebration of shared meals, particularly family meals, has also been challenged by feminist studies. Research into how households manage food provision has shown that family foodways are, to a great extent, still dictated by patriarchal values that strongly demonize mothering practices that deviate from the norms of good and caring mothering, including self-prepared meals enjoyed with the whole family (Kinser 2017).

Conceptualizations of the elements of meals and so-called proper meals are also changing. For instance, in Britain, the "meat and two veg" ideal still exists, but it is increasingly reserved for special occasions, and raw ingredients are often mixed with ready-prepared convenience foods in home cooking (Gatley et al. 2014). Since the 1950s, midday meals in Britain have become much simpler, evolving from typically hot meals to sandwich-based meals. Evening meals still exhibit a staple-and-center structure, but more pastas (probably with mixed ingredients) as well as pizzas and burgers are eaten than in earlier decades, particularly among younger people (Yates and Warde 2015). In the Nordic countries, it appears that, from the late 1990s to the early 2010s, dinners have increasingly become one-course meals - "platefuls" - that include a few more components than before. Nordic dinners are still dominated by meat dishes, but vegetarian dishes are becoming somewhat more popular (Holm et al. 2015). At the same time, particularly on weekends, restaurants and cafés offer meals that combine the conventional meals, and new names for such hybrids are emerging. The most common is probably brunch, a portmanteau of breakfast and lunch. Terms describing the combination of lunch and dinner have also recently emerged, including lunner, linner, and lupper (for lunch and supper). Such examples show that meals are not a static system but continually evolve, not only in what is eaten but also in how different meals are imaginatively combined in new constellations.

Another challenge to meals comes from concerns about the sustainability of our current foodways. This relates particularly to the position of meat and other animal-based foods in contemporary meals. As noted above, meat has a central position in Western meals and is ascribed many positive meanings (Latvala et al. 2012). Questioning its status may increase tensions in families if some family members would like to reduce the share of animal-based foodstuffs in family meals while others would not. As Roth (2005) has noted, a family member who adopts a vegetarian diet in a meat-eating family chal lenges the family foodways and threatens the family's homeostasis by redefining the meanings of meat and turning upside down the hierarchy of various foodstuffs in the family's meal system. The vegetarian may be interpreted as questioning the entire family system by refusing to eat meat, which signifies maleness, power, strength, and, typically, male dominance in families. The family meal may then become an arena of contention because, by refusing food that other family members would happily eat, the vegetarian challenges the family identity and puts into question his or her membership in the unit. In such a situation, the power relations within the family are renegotiated, and families use diverse strategies to reconstruct family cohesion. According to Roth (2005), because families know that vegetarianism is (often) not only about declining meat but also about embracing an ideology that resists the dominant culture's values, institutions, and 
practices, they may dismiss vegetarianismas "just a phase," pressure the vegetarian to eat meat, challenge the moral justification of vegetarianism, or force the vegetarian to develop strategies of conflict avoidance, such as agreeing to eat meat occasionally or to refrain from discussing the moral justifications of vegetarianism.

Social scientists in the 1980s and increasingly thereafter have noted that meal patterns in Western countries are changing due to various societal changes, particularly women's increasing participation in working life, the availability of alternatives to meals cooked from scratch, increasing incomes, the declining share of food expenditure in the total consumption expenditure of households, and the increasing number of restaurants and cafés that offer alternatives to home meals (see, e.g., Gronow and Holm 2019; Murcott 1997, 2019; Yates and Warde 2015; Warde 1997, 2016). We are undoubtedly seeing a trend toward less formal eating, "lighter" meals (i.e., having simpler structures), snacking, and less ritualistic meals (Marshall 2005; Gronow and Holm 2019), but this does not necessarily mean that meals as a social institution are threatened in any serious way. As shown above, the organization of meals was not stable in earlier decades either. When society changes, patterns of meals and eating change too. The position of the meal as a central social institution structuring everyday life (Mäkelä 2009) and as a "lived experience" (Lalonde 1992, p. 75) does not seem seriously threatened, although the number of meals eaten alone may increase with the growing number of single households.

As Marshall (1993) has noted, "Different meals are marked by the time at which they occur, the frequency with which they occur, people who are present at the meal, the number of participants, the nature of the food served, the food combinations, the purpose of the event and the time spent on the food preparation, consumption and the duration of the meal" (p. 284). When one or more of these characteristics and their relations evolve over time, meals change too, but it seems that Marshall's proposition that "meals have become the things that occur between snacks" (1993, p. 286) holds true only in the literal sense that meals and snacks necessarily alternate during the day. People in Western countries still eat meals, major and minor, and little evidence suggests that snacks threaten their cultural and social significance in any serious way. However, Marshall rightly notes that meals are becoming less formal and that what were previously classified as "minor meal s," i.e., cold meals and meals with fewer elements, are becoming more common.

\section{The Future of Meals}

What does the future of meals look like? Are shared meals challenged or even on their way to vanishing, as assumed in much contemporary writing? Is eating going to be based more and more on whims, personal tastes, genetic predispositions, nutrigenetic diets, and laboratory-grown ingredients that scarcely resemble the plants or animals from whose cells they are produced? Are the demands of sustainability or the need to adapt to climate change and declining biodiversity going to restrict our diets in profound ways?

These large questions surround the discourse on meals and eating patterns in the late 2010s, and the answers will depend on political decisions; cultural, societal, technological, and economic developments; and changes in the biosphere and our living environment now and in the coming decades. The current patterns of eating are challenged by health, ethical, and ecological concerns, and the necessary changes are going to affect the content of future meals.

However, our analysis suggests that there is no reason to believe that the position of the meal in Western patterns of eating is threatened in a serious way, simply because meals have such a strong grip on the sequential arrangements of everyday life. In addition, individualism and commensality 
are likely to coexist in the future (Mäkelä 2009; Gronow and Holm 2019). Even though food and its origins may change, the role of meals as the essential social glue between people remains unchallenged because sharing food seems to be an essential part of humanity.

What will probably change is the food on our plates and how we organize our eating in a way that entails as little ecological burden as possible. This will mean reducing the share of animal produce in meals and replacing it with plant-based options as well as making greater efforts to avoid wasting food. One of the authors of this chapter noted in 2009 that "the heated discussion on climate change pushes forward increasing awareness of sustainability of both the production and consumption of food" (Mäkelä2009, p. 46). In the ten years since that remark was made, the question of climate change has become more pressing than ever (Willett et al. 2019). Solving it by changing patterns of eating may be easier said than done, however, due to the deeply ingrained nature of our routines and habits of eating as well as the failure (so far) of policy-makers to adopt serious measures to alter animal-based agricultural practices. Meat and dairy products are part and parcel of Western meals, and changing that will require a profound change in what is produced on farms; manufactured in the food industry; sold in grocery stores, cafés, and restaurants; and prepared in homes and in public food provision. The same goes for addressing food waste; all actors in the food system will need to reduce the amount of wasted food, which will not happen without a reordering of the system of food provision. The reasons for food's being waste are very practical. No one in the food system wants to waste food, but the objectives, practices, and unexpected events in the flow of business and daily life generate excess and, consequently, waste (see, e.g., Evans 2012; Murcott 2019). The focus of efforts to reduce waste should, therefore, be on those practical circumstances rather than on educational campaigns and blaming consumers.

Anne Murcott (1986) has pointed out that, to the same degree that "weare what we eat," it may be argued that "we eat what weare" (p. \#). Our social identities are inextricably tied to what, where, how, and when we eat. The need to look at food from the perspective of sustainability gives Murcott's notion extra strength by linking our "eating identity" to the gl obal ecological and social challenges of our time. If we eat what we are, then sustainable eating should become a part of our social identities just as "we are what we eat" is understood to encourage people to eat healthily. But it must be added that what we eat is not a purely voluntary, autonomous choice; that choice is made amidst a myriad of cultural norms and meanings, social relations, institutional arrangements, and political regulations, and it should go without saying that this is particularly true for the many surviving on meagre incomes who struggle every day to feed and care for themselves and their families. "We eat what we are" must be understood as pertaining not only to individuals as diners, consumers, and parents but also to everyone in our roles as citizens, farmers, educators, lobbyists, politicians, government officials, or employees in the manufacturing and retail food systems. What we eat in our future meals will depend on all of these as well as on the economic costs associated with the transition to more sustainable diets. 